\title{
Trends in Anatomy and Physiology
}

\section{Honey Extracts Exhibit Cytopro- tective Properties against UVB- Induced Photo-damage in Human Experimental Skin Models}

\author{
Konstantinos Gardikis* \\ Reseach and Development Department, APIVITA SA, Industrial Park of \\ Markopoulo Mesogaias, Athens, Greece
}

UV Radiation (UVR) is one of the main causes of various skin disorders. Depending on the wavelength, the duration of the exposure and factors that concern skin physiology and structure, UVR may have detrimental effects on skin, varying from triggering of aging mechanisms and immunosuppression to DNA damage and carcinogenesis. In parallel, the link between air pollution, UVR and skin carcinogenesis has been demonstrated by a significant number of epidemiological studies. Especially, the accumulation of damages caused by UV radiation and air pollution are proven to have several effects on skin, including chronic inflammation, immunosuppression, atrophy and aging. Nowadays it is more evident than ever that products for skin application, such as traditional cosmetics or cosmeceuticals, may play a very important role in the preservation of the overall health of population - apart from the obvious well-being target. Especially in large cities where the above factors - air pollution and UVR - coincide, there is an emerging need for development of products that are effective in terms of protection from environmental aggressors. These products should optimally be based in safe, sustainable, and natural ingredients that demonstrate proven efficacy in terms of protection.

Honey has been widely recognized as such an ingredient. Its use since ancient times, its sweet taste and its abundancy - despite the recent challenges imposed to bee populations because of environmental issues -make it ideal as a raw material for many human applications, beyond the per so use. Honey is a rather

*Corresponding author: Konstantinos Gardikis, Reseach and Development Department, APIVITA SA, Industrial Park of Markopoulo Mesogaias, Athens Greece, Tel: +30 2155707225/+30 6974899959; Fax: +30 2102843580 E-mail: gardikis-k@apivita.com

Citation: Gardikis K (2020) Honey Extracts Exhibit Cytoprotective Properties against UVB-Induced Photo-damage in Human Experimental Skin Models. Trends Anat Physiol 3: 009.

Received: September 30, 2020; Accepted: October 07, 2020; Published: October 15,2020

Copyright: (c) 2020 Gardikis K, et al. This is an open-access article distributed under the terms of the Creative Commons Attribution License, which permits unrestricted use, distribution, and reproduction in any medium, provided the original author and source are credited. complicate and non-consistent mixture of molecules. It is mainly constituted, apart from water, from sugars, glucose and fructose. It also contains amino acids, organic acids, vitamins and minerals. In small concentrationsit contains flavonoids and phenolic acids that seem to play in important role in the bioactivity of honey. It has been reported that bioactive compounds are similar in different types of honey, though the metabolic fingerprint seems quite different due to varying concentrations of the ingredients. It is no surprise that some honey extracts may have very different bioactivity than others, though they contain very similar bioactive substances.

Due to numerous studies, several types of honey have been reported to exhibit antimicrobial, antifungal, antioxidant, anti-inflammatory and anti-tumor activities. As for the antioxidant activity of honey, it is attributed to the flavonoids and organic acids it contains. The photoprotective activity of honey, that may to a point be linked with antioxidant mechanisms, has been poorly investigated. The recent research paper by Karapetsas et al. [1] demonstrated the capacity of several honey extracts to protect $\mathrm{HaCaT}$ cells from UVB radiation while they exhibited antioxidant and antimutagenic capacity. Also they were found to downregulate metalloproteinases in reconstituted human skin tissue models, demonstrating a potential for prevention of photoaging. There was a correlation between the total phenolic content and ABTS antioxidant capacity, though no correlation with DPPH antioxidant capacity. Furthermore, no significant correlation between total flavonoid count and antioxidant capacity was found, but this may be attributed to the low concentrations. What is of most interest is that two honey extracts, that did not demonstrate the highest flavonoid content and that were not statistically different from other extracts in terms of total phenolic content and in vitro antioxidant capacity, demonstrated significantly higher antioxidant activity in $\mathrm{HaCaT}$ cell under UVB exposure conditions, effectively protecting cells from UVB induced DNA damage [2]. This finding could be probably attributed to differences in the concentration of specific metabolites, mainly phenolic compounds, and not in the overall concentration of such compounds. It is undoubtful that the metabolic profile of honey - and especially the phenolic categories - should play an important role in the bioactivity mentioned above. The two honey samples come from very different areas, southern and central Crete, with very different vegetation, as depicted by the melissopalynological analysis [3].

A challenge implied by the current publication is clearly the correlation between metabolites of honey and specific concentration of them-with bioactivity, primarily in cellular level. Already, Manuka honey has been assessed and recognized for bioactivity related to the concentration of a specific molecule, methylglyoxal. The situation with other types of honey, such as thyme, fir, heather etc is quite different as the bioactivity is not expected from a single molecule, but from a combination of them. In this perspective, current advanced metabolomic analysis could be very useful [4]. Once the bioactivity of each honey metabolite has been identified, then the bioactivity of small fractions of the could be assessed too. What be of much interest is the correlation of such groups of molecules, and of their 
concentration, with the flora composition of different areas, as it is known that these are molecules collected from plants. This could prove to be the indication of specific "terroirs" for the placement of beehives by beekeepers in order to be able to produce honey with specific medicinal properties. By thorough research honey -for skin applications - could be transformed from a mild soothing and hydrating agent, to a powerful ingredient that protects skin from photoaging - including DNA damages that may lead to cancer and other medical conditions. Since there are reports on the activity of honey against other environmental stressors too, honey produced in a specific, controlled way, could prove a valuable ingredient for the preservation of the total health of a population - and in parallel a means to significantly enhance local economies. The scientific tools are present and the preliminary data convincing.

\section{References}

1. Karapetsas A, Voulgaridou GA, Iliadi D, Tsochantaridis I, Michail P, et al. (2020) Honey Extracts Exhibit Cytoprotective Properties Against UVB-Induced Photodamage in Human Experimental Skin Models. Antioxidants 9: 566.

2. Siddiqui AJ, Musharraf SG, Choudhary MI, Rahman AU (2017) Application of analytical methods in authentication and adulteration of honey. Food Chem 217: 687-698.

3. Premratanachai P, Chanchao C (2014) Review of the anticancer activities of bee products. Asian Pac J Trop Biomed 4: 337-344.

4. Israili ZH (2014) Antimicrobial properties of honey. Am J Ther 21: 304323. 


\section{II \\ нетам}

Advances In Industrial Biotechnology | ISSN: 2639-5665

Advances In Microbiology Research | ISSN: 2689-694X

Archives Of Surgery And Surgical Education | ISSN: 2689-3126

Archives Of Urology

Archives Of Zoological Studies | ISSN: 2640-7779

Current Trends Medical And Biological Engineering

International Journal Of Case Reports And Therapeutic Studies | ISSN: 2689-310X

Journal Of Addiction \& Addictive Disorders | ISSN: 2578-7276

Journal Of Agronomy \& Agricultural Science | ISSN: 2689-8292

Journal Of AIDS Clinical Research \& STDs | ISSN: 2572-7370

Journal Of Alcoholism Drug Abuse \& Substance Dependence | ISSN: 2572-9594

Journal Of Allergy Disorders \& Therapy | ISSN: 2470-749X

Journal Of Alternative Complementary \& Integrative Medicine | ISSN: 2470-7562

Journal Of Alzheimers \& Neurodegenerative Diseases | ISSN: 2572-9608

Journal Of Anesthesia \& Clinical Care | ISSN: 2378-8879

Journal Of Angiology \& Vascular Surgery | ISSN: 2572-7397

Journal Of Animal Research \& Veterinary Science | ISSN: 2639-3751

Journal Of Aquaculture \& Fisheries | ISSN: 2576-5523

Journal Of Atmospheric \& Earth Sciences | ISSN: 2689-8780

Journal Of Biotech Research \& Biochemistry

Journal Of Brain \& Neuroscience Research

Journal Of Cancer Biology \& Treatment | ISSN: 2470-7546

Journal Of Cardiology Study \& Research | ISSN: 2640-768X

Journal Of Cell Biology \& Cell Metabolism | ISSN: 2381-1943

Journal Of Clinical Dermatology \& Therapy | ISSN: 2378-8771

Journal Of Clinical Immunology \& Immunotherapy | ISSN: 2378-8844

Journal Of Clinical Studies \& Medical Case Reports | ISSN: 2378-8801

Journal Of Community Medicine \& Public Health Care | ISSN: 2381-1978

Journal Of Cytology \& Tissue Biology | ISSN: 2378-9107

Journal Of Dairy Research \& Technology | ISSN: 2688-9315

Journal Of Dentistry Oral Health \& Cosmesis | ISSN: 2473-6783

Journal Of Diabetes \& Metabolic Disorders | ISSN: 2381-201X

Journal Of Emergency Medicine Trauma \& Surgical Care | ISSN: 2378-8798

Journal Of Environmental Science Current Research | ISSN: 2643-5020

Journal Of Food Science \& Nutrition | ISSN: 2470-1076

Journal Of Forensic Legal \& Investigative Sciences | ISSN: 2473-733X

Journal Of Gastroenterology \& Hepatology Research | ISSN: 2574-2566
Journal Of Genetics \& Genomic Sciences | ISSN: 2574-2485

Journal Of Gerontology \& Geriatric Medicine | ISSN: 2381-8662

Journal Of Hematology Blood Transfusion \& Disorders | ISSN: 2572-2999

Journal Of Hospice \& Palliative Medical Care

Journal Of Human Endocrinology | ISSN: 2572-9640

Journal Of Infectious \& Non Infectious Diseases | ISSN: 2381-8654

Journal Of Internal Medicine \& Primary Healthcare | ISSN: 2574-2493

Journal Of Light \& Laser Current Trends

Journal Of Medicine Study \& Research | ISSN: 2639-5657

Journal Of Modern Chemical Sciences

Journal Of Nanotechnology Nanomedicine \& Nanobiotechnology | ISSN: 2381-2044

Journal Of Neonatology \& Clinical Pediatrics | ISSN: 2378-878X

Journal Of Nephrology \& Renal Therapy | ISSN: 2473-7313

Journal Of Non Invasive Vascular Investigation | ISSN: 2572-7400

Journal Of Nuclear Medicine Radiology \& Radiation Therapy | ISSN: 2572-7419

Journal Of Obesity \& Weight Loss | ISSN: 2473-7372

Journal Of Ophthalmology \& Clinical Research | ISSN: 2378-8887

Journal Of Orthopedic Research \& Physiotherapy | ISSN: 2381-2052

Journal Of Otolaryngology Head \& Neck Surgery | ISSN: 2573-010X

Journal Of Pathology Clinical \& Medical Research

Journal Of Pharmacology Pharmaceutics \& Pharmacovigilance | ISSN: 2639-5649

Journal Of Physical Medicine Rehabilitation \& Disabilities | ISSN: 2381-8670

Journal Of Plant Science Current Research | ISSN: 2639-3743

Journal Of Practical \& Professional Nursing | ISSN: 2639-5681

Journal Of Protein Research \& Bioinformatics

Journal Of Psychiatry Depression \& Anxiety | ISSN: 2573-0150

Journal Of Pulmonary Medicine \& Respiratory Research | ISSN: 2573-0177

Journal Of Reproductive Medicine Gynaecology \& Obstetrics | ISSN: 2574-2574

Journal Of Stem Cells Research Development \& Therapy | ISSN: 2381-2060

Journal Of Surgery Current Trends \& Innovations | ISSN: 2578-7284

Journal Of Toxicology Current Research | ISSN: 2639-3735

Journal Of Translational Science And Research

Journal Of Vaccines Research \& Vaccination | ISSN: 2573-0193

Journal Of Virology \& Antivirals

Sports Medicine And Injury Care Journal | ISSN: 2689-8829

Trends In Anatomy \& Physiology | ISSN: 2640-7752

Submit Your Manuscript: https://www.heraldopenaccess.us/submit-manuscript 